\title{
Withdraw of Insurers from ACA Markets Leaving Many Southwest Patients with Few or No Choices
}

Thirty-one percent of the nation's counties are projected to have only one insurer offering health plans on the Affordable Care Act's (ACA) exchanges next year, according to the nonpartisan Kaiser Family Foundation (1). Another $31 \%$ are projected to have only be only two. Most of the likely one-insurer counties are predominantly rural (Figure 1).

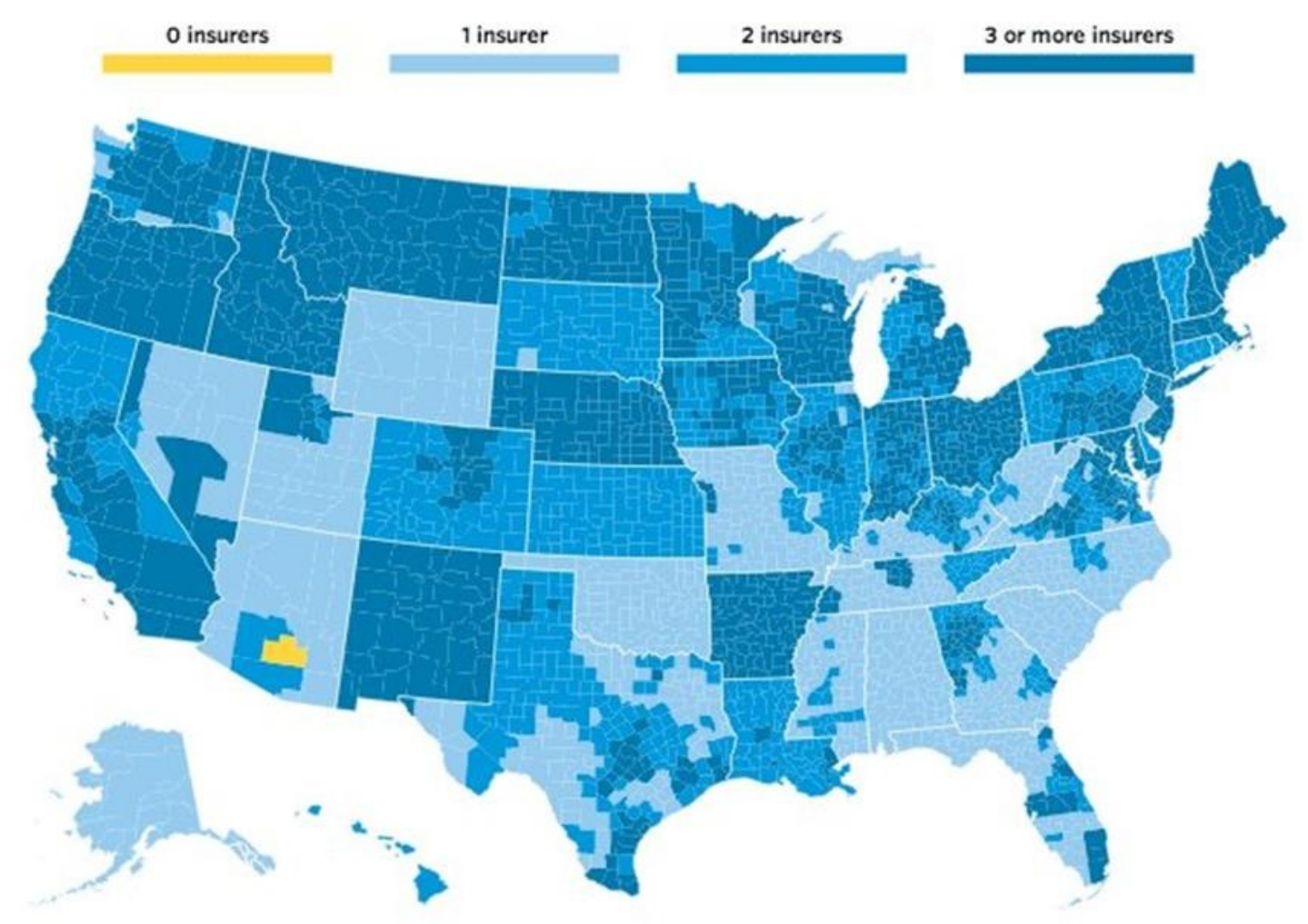

Figure 1. Estimated number of insurers participating in Affordable Care Act exchanges by county, 2017.

Particularly hard hit is Arizona where most of the rural portions of the state will have only one insurer and Pinal County will have none. Rural Nevada is similarly affected along with Utah, Wyoming, Oklahoma and much of the Southeast US.

That would give exchange customers in large areas of the U.S. far less choice than they had this year, when only $7 \%$ of counties had one insurer and $29 \%$ had two (Figure 2). 


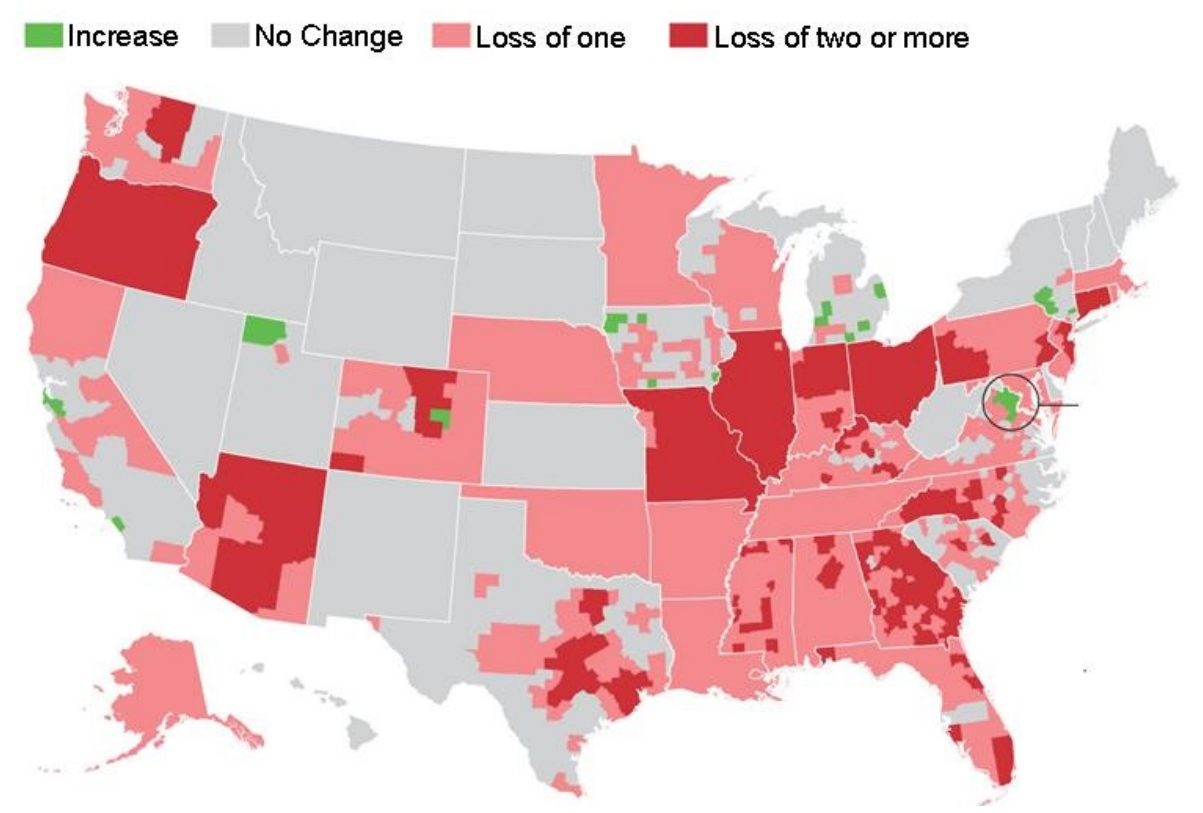

Figure 2. Net changes in number of insurers compared to 2016.

Many insurers are losing money on the health plans they sell through the exchanges. Insurance giants UnitedHealth, Humana, and Aetna have cited heavy losses as the reason for withdrawing from ACA marketplaces (2). The insurers that remain are in some cases seeking sharp premium increases for next year, trying to get back in the black amid higher-than-expected costs.

The marketplaces were supposed to hold down prices and expand choice by fostering competition among insurers. A concern when the exchanges were set up was that they might eventually reach the "tipping point". This is the point where too many sick patients with high health care costs are enrolled in the exchanges. Their high costs lead to higher insurance premiums driving the young and healthy enrollees out of the exchanges. According to the insurers the young and healthy enrollees low costs are necessary to balance out claims ledgers. President Obama has called for the creation of a public insurance option to compete alongside private plans in places where competition is limited.

\section{References}

1. Cox C, Semanskee A. Preliminary data on insurer exits and entrants in 2017 affordable care act marketplaces. Kaiser Health News. August 28, 2016.

Avialble at: http://kff.org/health-reform/issue-brief/preliminary-data-on-insurerexits-and-entrants-in-2017-affordable-care-act-marketplaces/ (accessed 8/29/16).

2. Mathews AW, Armour S. Health insurers' pullback threatens to create monopolies. Wall Street Journal. August 28, 2016. Available at: http://www.wsj.com/articles/health-insurers-pullback-threatens-to-createmonopolies-1472408338 (accessed 8/29/16). 